\title{
Methylphenidate Administration to Juvenile Rats Alters Brain Areas Involved in Cognition, Motivated Behaviors, Appetite, and Stress
}

\author{
Jason D. Gray, ${ }^{1}$ Michael Punsoni, ${ }^{1}$ Nora E. Tabori, ${ }^{1,3}$ Jay T. Melton, ${ }^{1}$ Victoria Fanslow, ${ }^{1}$ Mary J. Ward, ${ }^{2}$ Bojana Zupan, ${ }^{1}$ \\ David Menzer, ${ }^{1}$ Jackson Rice, ${ }^{1}$ Carrie T. Drake, ${ }^{1}$ Russell D. Romeo, ${ }^{3}$ Wayne G. Brake, ${ }^{4}$ Annelyn Torres-Reveron, ${ }^{1}$ and \\ Teresa A. Milner ${ }^{1,3}$ \\ ${ }^{1}$ Division of Neurobiology, Department of Neurology and Neuroscience and ${ }^{2}$ Department of Pediatrics, Weill-Cornell Medical College, New York, New York \\ 10021, ${ }^{3}$ Harold and Margaret Milliken Hatch Laboratory of Neuroendocrinology, The Rockefeller University, New York, New York 10021 , and ${ }^{4}$ Centre for \\ Studies in Behavioral Neurobiology, Department of Psychology, Concordia University, Montreal, Canada H4B 1R6
}

Thousands of children receive methylphenidate (MPH; Ritalin) for attention deficit/hyperactivity disorder (ADHD), yet the long-term neurochemical consequences of MPH treatment are unknown. To mimic clinical Ritalin treatment in children, male rats were injected with MPH ( $5 \mathrm{mg} / \mathrm{kg}$ ) or vehicle twice daily from postnatal day 7 (PND7)-PND35. At the end of administration (PND35) or in adulthood (PND135), brain sections from littermate pairs were immunocytochemically labeled for neurotransmitters and cytological markers in 16 regions implicated in MPH effects and/or ADHD etiology. At PND35, the medial prefrontal cortex (mPFC) of rats given MPH showed 55\% greater immunoreactivity (-ir) for the catecholamine marker tyrosine hydroxylase (TH), $60 \%$ more Nissl-stained cells, and $40 \%$ less norepinephrine transporter (NET)-ir density. In hippocampal dentate gyrus, MPH-receiving rats showed a 51\% decrease in NET-ir density and a $61 \%$ expanded distribution of the new-cell marker PSA-NCAM (polysialylated form of neural cell adhesion molecule). In medial striatum, TH-ir decreased by $21 \%$, and in hypothalamus neuropeptide Y-ir increased by $10 \%$ in MPH-exposed rats. At PND135, MPH-exposed rats exhibited decreased anxiety in the elevated plus-maze and a trend for decreased TH-ir in the mPFC. Neither PND35 nor PND135 rats showed major structural differences with MPH exposure. These findings suggest that developmental exposure to high therapeutic doses of MPH has short-term effects on select neurotransmitters in brain regions involved in motivated behaviors, cognition, appetite, and stress. Although the observed neuroanatomical changes largely resolve with time, chronic modulation of young brains with MPH may exert effects on brain neurochemistry that modify some behaviors even in adulthood.

Key words: Ritalin; prefrontal cortex; hippocampus; striatum; hypothalamus; ADHD

\section{Introduction}

Attention deficit/hyperactivity disorder (ADHD) affects $2-18 \%$ of children in the United States, with higher prevalence among boys (Silver, 1999; Marshall, 2000; Hechtman, 2006). ADHD is characterized by developmentally inappropriate symptoms of impulsivity, inattentiveness, and overactivity (Sagvolden and Sergeant, 1998). Methylphenidate (MPH; Ritalin) is one of the most commonly prescribed drugs for alleviating ADHD symptoms and is efficacious in reducing hyperactivity and improving

Received Jan. 10, 2007; revised May 29, 2007; accepted May 31, 2007.

This work was supported by National Institutes of Health Grants R21MH63769, R01 DA08259, and P01 HL18974 (T.A.M.) and by the Natural Sciences and Engineering Research Council of Canada (W.G.B.). We thank Scott Herrick, Dr. Michael Glass, Katherine Mitterling, Vladimir Znamensky, Nyema Woart, and Denise Garcia (all at Weill-Cornell Medical College) for technical assistance, Dr. Rodger L. Foltz (Center for Human Toxicology, University of Utah, Salt Lake City, UT) for determining MPH levels in plasma samples from pilot studies, and Dr. Randy Blakely (Vanderbilt University School Medical (enter, Nashville, Tennessee) for generously providing antiserum to the norepinephrine transporter. We also thank Drs. Virginia M. Pickel (Weill-Cornell Medical College) and Larry B. Silver for their helpful discussions.

Correspondence should be addressed to Dr. Teresa A. Milner, Division of Neurobiology, Weill-Cornell Medical College, 411 East 69th Street, New York, NY 10021. E-mail: tmilner@mail.med.cornell.edu.

D0I:10.1523/JNEUROSCI.0109-07.2007

Copyright $\odot 2007$ Society for Neuroscience $\quad$ 0270-6474/07/277196-12\$15.00/0 attentiveness (Popper, 1997; Angold et al., 2000). Although the benefits of $\mathrm{MPH}$ for ADHD symptoms are well documented, little is known about the long-term impacts of $\mathrm{MPH}$ on brain development. This issue has become increasingly urgent in recent years, because the number of MPH prescriptions has risen dramatically, children are beginning MPH treatment as young as 2 years of age (Zito et al., 2000), and the duration of MPH treatment has been lengthening, sometimes lasting into adulthood (Solanto, 1998; Angold et al., 2000).

The acute and short-term actions of MPH in the brain are relatively well established. MPH treatment blocks the dopamine transporter, increasing extracellular dopamine levels; changes are seen in dopamine $\mathrm{D}_{2}$ receptors and in dopaminergic transmission in at least the striatum and prefrontal cortex (Gatley et al., 1996; Kuczenski and Segal, 1997; Volkow et al., 1997, 1998, 1999a,b, 2001; Russell et al., 1998; Izenwasser et al., 1999). Additionally, MPH affects noradrenergic and serotonergic systems by blocking the norepinephrine and serotonin transporters, although affinity is lower than for the dopamine transporter (Gatley et al., 1996; Kuczenski and Segal, 1997). Changes in monoaminergic transmission have been observed in the nucleus 
accumbens, temporal cortex (including the hippocampus), cerebellum, and amygdala (Kuczenski and Segal, 1997; Volkow et al., 1997).

Persistent alteration of monoaminergic transmission triggered by chronic MPH during development can potentially have cytoarchitectural and neurochemical consequences. Normal brain development requires the coordinated maturation of many processes occurring in a temporally and regionally dependent manner (Barone et al., 2000; Rice and Barone, 2000). Monoamines are important regulators of these processes, and altering them with MPH during development may profoundly affect synaptogenesis, myelination, and gliogenesis (Levitt et al., 1997; Barone et al., 2000; Rice and Barone, 2000). The effects of MPH are potentially most pronounced in regions associated with cognition and learning (e.g., hippocampus and cerebral cortex), which are at their peak of synaptogenesis during childhood and adolescence in humans and rats (Bayer et al., 1993; Klintsova and Greenough, 1999; Rice and Barone, 2000).

To study these issues, we used a rat model that mimics therapeutic doses of $\mathrm{MPH}$ given to children and adolescents with ADHD. Brain regions implicated in ADHD, cognition, stress, appetite, and/or attentional processes were immunocytochemically assessed for changes in cytoarchitecture and neurotransmitters in male rats immediately after 4 weeks of MPH administration and 3 months after MPH administration. Neurotransmitter systems examined included dopamine, norepinephrine, serotonin, and acetylcholine. Additionally, weight gain and long-term effects on anxiety behavior were measured to confirm the relevance of the model (Rapport and Moffitt, 2002; McFadyenLeussis et al., 2004).

\section{Materials and Methods}

\section{Animals}

All methods were conducted in accordance with the 1996 National Institutes of Health Guide for the Care and Use of Laboratory Animals and were approved by the Weill-Cornell Medical College Institutional Animal Care and Use Committee. Timed-pregnant Sprague Dawley female rats $(n=12)$ were obtained from Taconic Farms (Chatham, NY). Mother rats were housed individually in free-standing "shoe-box" cages (model 6; dimensions, $30.80 \times 59.37 \times 22.86 \mathrm{~cm}$; Thoren Caging Systems, Hazleton, PA) and kept in a reversed light cycle room (lights off at 11:00 A.M. and lights on at 11:00 P.M.) equipped with red (GBX-2) darkroom safelights (Eastman Kodak, Rochester, NY) and kept at an ambient temperature of $21-24^{\circ} \mathrm{C}$. After weaning [postnatal day 21 (PND21)] and until the termination of the experiment, littermate sex-matched rat pairs $(n=80)$ were pair-housed in cages stacked in ventilator racks (cage model 4; dimensions, $30.80 \times 30.80 \times 18.72 \mathrm{~cm}$; Thoren Caging Systems). The air exchange rate inside the cages during normal operation was 80 changes/h.

\section{Choice of experimental model}

The most common medication for the treatment of ADHD is MPH (Swanson et al., 1998; Jensen et al., 1999; Zito et al., 2000). The diagnosis of ADHD is usually made before the age of 7 years or in the first years of school (Gordon, 1999). However, recent clinical trials using preschoolers ages 3-5 years have demonstrated that MPH is effective in reducing ADHD symptoms but leads to increased side effects, including insomnia, weight loss, and decreased appetite (Wigal et al., 2006). In general, the sequence of regional brain development in humans and rodents is similar; however, regional development of the rodent proceeds on a timeline of days compared with months in humans (Bayer et al., 1993; Rice and Barone, 2000). We chose to start administering MPH to rats at PND7 because at this time point the first adult-like neurons are observed in the rat hippocampal dentate gyrus (Jones et al., 2003), and synaptogenesis and neuronal growth are actively occurring (Bayer et al., 1993). MPH administration continued until PND35 because at this age the matura- tion level of the brain telencephalon corresponds to that observed in adolescent humans (Bayer et al., 1993; Dobbing and Sands, 2000; Romijn et al., 2000). Male rats were the focus of the analysis, because boys have higher rates of ADHD than girls (Angold et al., 2000).

$\mathrm{MPH}$ is metabolized into the less-active p-hydroxylated-MPH more readily in rats than in humans (15\% in rats compared with $1-4 \%$ in humans) (Faraj et al., 1974; Wargin et al., 1983; Torres-Reveron and Dow-Edwards, 2005); some of this may be attributable to the route of administration because the oral route reduces the percentage of metabolism to 3\% in rats (Faraj et al., 1974; Wargin et al., 1983). Intraperitoneal administration is twice as potent as oral administration in terms of increasing extracellular dopamine and stimulating locomotion (Gerasimov et al., 2000). MPH was given during the active cycle (dark phase of the photo period) because rats are nocturnal animals, and MPH is given to control symptoms during the active (diurnal) period in humans (Angold et al., 2000). In addition, rats were assessed at two time points (PND35 and PND135) to determine whether any of the changes that may occur from $\mathrm{MPH}$ exposure during development persist later into adulthood.

\section{MPH administration}

On PND3, the litters were sexed and culled to 10 pups per litter. Males and females were included in this phase of the experiment to keep litters a consistent size and normal male-female composition. The paws of each pup were tattooed with India ink so that control and MPH-receiving rats could be distinguished by the experimenters but not by the mother rat (Brake et al., 1999). From PND7 to PND35, littermate sex-matched pairs of rat pups were weighed and administered either $5 \mathrm{mg} / \mathrm{kg}$ D,L-threoMPH (obtained from National Institute on Drug Abuse, Research Triangle Park, NC) in saline or an equal volume of saline intraperitoneally twice daily, $6 \mathrm{~h}$ apart during their dark (i.e., active) cycle. At the end of the administration phase, male littermate pairs of rats from each group were divided into two groups. Group 1 was examined immediately after drug administration (PND35), whereas group 2 was examined 3 months after cessation of MPH drug administration (PND135). During the cessation period, PND135 rats were weighed every 3 or $4 \mathrm{~d}$. Repeated measures of weight were evaluated for systematic variation by litter and sex, using repeated-measures ANOVA (RMANOVA). Differences were considered significant at $p<0.05$.

\section{Behavioral tests}

To assess the long-term effects of developmental exposure to MPH on anxiety-like behaviors, two behavioral tests were performed on male rats between PND130 and PND134 using previously described procedures (Ramos and Mormede, 1998). For both behavioral tests, the experimenter was blind to the administration category and was not in the room during testing.

Open-field test. On the day of testing, each rat was transferred to the open-field testing room. Tests were conducted between 1:00 and 4:00 P.M. The floor of the apparatus was a $14 \times 14 \mathrm{~cm}$ grid composed of 25 squares ( 16 outer and 9 inner). A $150 \mathrm{~W}$ light bulb and the video camera were positioned above the apparatus, illuminating the open field and recording the rat's behavior. Each rat was placed in the same corner square of the open field at the beginning of the 5 min test. All four paws had to cross the line of a center square to be considered an entry into the center of the open field. Time spent in the center of the open field compared with the squares closer to the walls (wall hugging) also was measured. At the end of the test, the rat was returned to its home cage, and the open-field apparatus was thoroughly cleaned with $30 \%$ ethanol.

Elevated plus-maze. Elevated plus-maze tests were conducted under dim red light illumination between 1:00 and 4:00 P.M. The elevated plus-maze was composed of two closed arms with high black plastic walls and two open arms. A video camera was positioned above the apparatus to record the behavior of the rat. Each rat was placed in the center of the elevated plus-maze (facing an open arm) at the beginning of the $5 \mathrm{~min}$ test. Similar to the open-field test, all four paws had to cross the entry of the open or closed arm to be considered an entry. Amount of time spent in the open arms compared with the closed arms was measured as well. At the end of the test, the rat was returned to its home cage, and the plusmaze was thoroughly cleaned with $30 \%$ ethanol. 
Statistical analyses. Latency, frequency data, and time spent in center or wall of the open-field test or open versus closed arms on the elevated plus-maze were analyzed by two-tailed Student's $t$ tests. Data were expressed as averages \pm SEM. Differences were considered significant at $p<0.05$.

\section{Immunocytochemical procedure}

Section preparation. On PND35 (group 1) or PND135 (group 2), six littermate pairs of male rats, each consisting of an MPH-administered and a saline-administered rat, were deeply anesthetized with sodium pentobarbital $(150 \mathrm{mg} / \mathrm{kg})$, and their brains fixed by aortic arch perfusion sequentially with the following: (1) $10-15 \mathrm{ml}$ of saline $(0.9 \%)$ containing $1000 \mathrm{U}$ of heparin; (2) $50 \mathrm{ml}$ of $3.75 \%$ acrolein and 2\% paraformaldehyde in $0.1 \mathrm{M}$ phosphate buffer (PB; pH 7.6); and (3) $200 \mathrm{ml}$ of $2 \%$ paraformaldehyde in PB (Milner and Veznedaroglu, 1992). After the perfusion, the brains were removed and cut into $5 \mathrm{~mm}$ coronal blocks using a brain mold (Activational Systems, Warren, MI) and postfixed for $30 \mathrm{~min}$ in the latter fixative. The brains were sectioned on a Leica (Bannockburn, IL) VT1000X Vibratome ( $40 \mu \mathrm{m}$ thick) and stored at $-30^{\circ} \mathrm{C}$ in cryoprotectant (30\% sucrose and $30 \%$ ethylene glycol in PB) until immunocytochemical processing. Before immunocytochemistry, sections from littermate rat pairs were rinsed in $\mathrm{PB}$, coded with hole punches, and pooled into single containers (Milner et al., 1997). Care was taken to match rostrocaudal levels of the paired sections so that nearidentical brain regions could be compared between groups. Sections were treated with $1 \%$ sodium borohydride in PB for $30 \mathrm{~min}$ to neutralize free aldehydes and rinsed thoroughly in PB. Sections then were rinsed in 0.1 M Tris-buffered saline (TS; pH 7.6) and incubated in $0.5 \%$ bovine serum albumin (BSA) in TS for $30 \mathrm{~min}$.

Brain regions analyzed and corresponding atlas levels. Coronal sections containing brain regions implicated in ADHD, animal models of hyperactivity (Grund et al., 2006), and/or learning and attentional processes (Castellanos et al., 2006) were selected for analysis using the Swanson (1992) atlas as a guide. Sixteen regions were examined: amygdala [central and basolateral nuclei; levels 27 and 28; anteroposterior (AP), -2.00 to $-2.45 \mathrm{~mm}$ from bregma], anterior cingulate cortex (levels $22-24 ;-4.60$ to $-1.33 \mathrm{~mm}$ from bregma), cerebellum (levels $53-55 ;-10.35$ to -10.85 $\mathrm{mm}$ from bregma), globus pallidus (levels $20-22 ;-0.46$ to $-4.60 \mathrm{~mm}$ from bregma), hippocampal formation (CA1, CA3, and dentate gyrus; levels $28-38$; -2.45 to $-5.65 \mathrm{~mm}$ from bregma), dorsomedial (DMH) and paraventricular (PVN) hypothalamic nuclei (levels $23-30 ;-1.08$ to $-3.25 \mathrm{~mm}$ from bregma), locus ceruleus (levels $51-52 ;-9.80$ to -10.10 $\mathrm{mm}$ from bregma), nucleus accumbens (core and shell; levels 12-14; +1.45 to $+0.95 \mathrm{~mm}$ from bregma), nucleus basalis (levels $17-23 ;-0.0$ to $-1.08 \mathrm{~mm}$ from bregma), prefrontal cortex (dorsal and medial; levels $8-10 ;+3.20$ to $+2.15 \mathrm{~mm}$ from bregma), raphe nuclei [dorsal and magnus; levels $44-45$ ( -7.60 to $-7.90 \mathrm{~mm}$ from bregma) and $49-51(-9.25$ to $-9.80 \mathrm{~mm}$ from bregma)], septal nuclei (medial septal nucleus and diagonal band of Broca; levels 15-16; +0.45 to $+0.10 \mathrm{~mm}$ from bregma), somatosensory cortex (primary; levels $27-29 ;-2.00$ to $-2.85 \mathrm{~mm}$ from bregma), striatum (13-16; +1.20 to $+0.10 \mathrm{~mm}$ from bregma), and substantia nigra and ventral tegmental area (levels $37-39 ;-5.25$ to -6.06 $\mathrm{mm}$ from bregma).

Antisera. Antisera and histological stains were selected to identify neurotransmitter systems implicated in ADHD and/or targeted by MPH (e.g., monoamines) and to identify particular cell populations known to develop postnatally (e.g., newly born cells in the dentate gyrus) or to be important for development (e.g., glial cells). All antisera have been well characterized and tested for specificity previously. More details for antisera are provided in the indicated references. To identify monoaminergic neurons and processes, a mouse monoclonal antibody to tyrosine hydroxylase (TH; diluted 1:10,000), the catecholamine-synthesizing enzyme, was obtained from Incstar (Stillwater, MN) (Milner et al., 1999). Dopaminergic neurons and processes were identified by using a polyclonal rat antiserum to the dopamine transporter (DAT; diluted 1:5000), obtained from Millipore (Billerica, MA) (Sesack et al., 1998). Noradrenergic neurons and processes were identified with a rabbit polyclonal antiserum to dopamine- $\beta$-hydroxylase (DBH; diluted 1:10,000), supplied by Dr. Cory Abate (University of Medicine and Dentistry of New
Jersey, Newark, NJ) (Joh and Ross, 1983), and a rabbit polyclonal antiserum to the norepinephrine transporter (NET; diluted 1:20,000), supplied by Dr. Randy Blakely (Vanderbilt University School of Medicine, Nashville, TN) (Miner et al., 2003). Serotonin neurons and processes were identified with a goat polyclonal antiserum to the serotonin transporter (SERT; diluted 1:5000), obtained from Santa Cruz (Brown and Molliver, 2000). Cholinergic neurons were identified by using a goat polyclonal antibody to vesicular acetylcholine transporter (VAChT; diluted 1:20,000), obtained from DiaSorin (Stillwater, MN) (Arvidsson et al., 1997). Selected neuropeptides were labeled using (1) a monoclonal mouse antibody to leucine-enkephalin (L-Enk; diluted 1:3000) obtained from DiaSorin (Drake et al., 2002); and (2) a polyclonal rabbit antiserum to neuropeptide Y (NPY; diluted 1:2000) obtained from Peninsula (Belmont, CA) (Milner and Veznedaroglu, 1992). Cell-specific markers also were used in this study. Thionin was used to visualize Nissl substance in cell bodies. To identify fibrous astrocytes, a mouse monoclonal antibody to glial fibrillary acidic protein (GFAP; diluted 1:6000) obtained from Millipore (Brezun and Daszuta, 2000) was used. To identify granule cell nuclei, a rabbit polyclonal antibody to the divergent homeobox protein PROX1 (diluted 1:10,000) obtained from Millipore was used (Elliott et al., 2001). To identify granule cell somata and dendrites, a mouse monoclonal antibody to calbindin (diluted 1:500; Sigma-Aldrich, St. Louis, MO) was used (Scharfman et al., 2000). A mouse monoclonal antibody to polysialylated form of neural cell adhesion molecule (PSA-NCAM; diluted 1:500) obtained from Millipore and a goat polyclonal antibody to doublecortin (DCX; diluted 1:2000) obtained from Santa Cruz Biotechnology (Santa Cruz, CA) were used to label newly born cells in the dentate gyrus (Francis et al., 1999; Brezun and Daszuta, 2000).

Immunocytochemical processing. Matched coronal sections containing the desired brain areas were processed for the immunocytochemical localization of the above antisera using the avidin-biotin complex method (Hsu et al., 1981). Briefly, tissue sections were incubated for $24 \mathrm{~h}$ at room temperature and for $24 \mathrm{~h}$ at $4^{\circ} \mathrm{C}$ in the specified dilution of antiserum in $0.1 \%$ BSA in TS, pH 7.6. All sections except those incubated in PSANCAM were incubated in a 1:400 dilution of biotinylated anti-Ig (IgG) against the species in which the primary antiserum was raised (Jackson ImmunoResearch, West Grove, PA) BSA/TS for $30 \mathrm{~min}$. Sections labeled for PSA-NCAM were incubated in biotinylated anti-mouse IgM (Cymbus Biotechnology, Flanders, NJ). After incubation in the secondary antibody, the sections were rinsed in TS and incubated in peroxidaseavidin complex (at twice the recommended dilution; Vector Laboratories, Burlingame, CA) for $30 \mathrm{~min}$ followed by development in $3,3^{\prime}$-diaminobenzidine (Sigma-Aldrich) and $\mathrm{H}_{2} \mathrm{O}_{2}$ in TBS for 6 min. Sections were mounted on slides previously coated with $1 \%$ gelatin and dried in a desiccator. The following day, the slides were dehydrated through a graded series of ethanols and coverslipped from xylene with DPX (Sigma-Aldrich).

Data analysis. Sections initially were analyzed qualitatively on a Nikon (Tokyo, Japan) E800 or 80i light microscope equipped with bright-field and differential interference contrast optics and a Micropublisher digital camera ( $Q$ Imaging, Barnaby, British Columbia, Canada). For the qualitative analysis, low-magnification $(2 \times$ or $4 \times)$ photomicrographs were taken of the brain region of interest (ROI) from matched areas in each littermate pair of sections. Photographs were laid side by side to determine whether MPH administration apparently altered the pattern or density of particular markers in the ROI. If differences were observed in the pattern of labeled fibers, higher-magnification photographs $(10 \times$ or $20 \times$ ) were taken of the ROI. If apparent differences in the density of a particular label were observed in three or more pairs of rats, quantitative densitometry was performed on the ROI using previously described methods (Pierce et al., 1999). For this, additional sections through the ROI were processed through the above immunocytochemical procedure using optimal, empirically derived dilutions of antisera appropriate for densitometry (TH, 1:250,000; DAT, 1:8000; NPY, 1:20,000) (Pierce et al., 1999; Chang et al., 2000). ROIs then were captured using a Dage CCD C72 camera and NIH Image 1.50 software on a Nikon 80i microscope (Pierce et al., 1999). The average pixel density (of 256 gray levels) for each ROI was determined using a $200 \mu \mathrm{m}$ circular probe. Three readings each from the background and ROI were taken and averaged before analysis. 
A

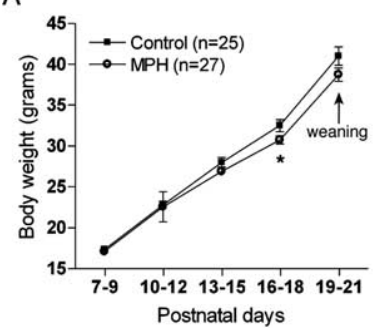

B

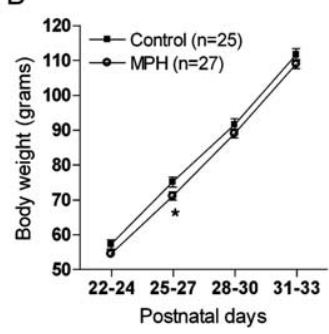

C

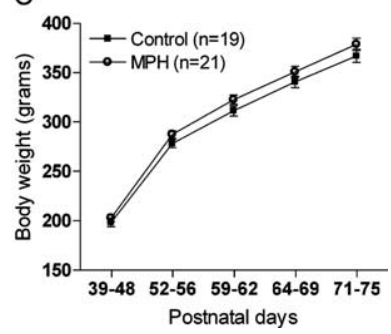

Figure 1. Body weight was reduced during developmental MPH administration but not after MPH administration was discontinued. A, Approximately 1 week after beginning MPH or saline administration at postnatal day 7, rats receiving MPH weighed significantly less than control littermates. $\boldsymbol{B}$, After weaning and during MPH administration, the weight difference was still significant. C, After cessation of administration at postnatal day 35 , rats that received MPH had weights similar to control rats. ${ }^{*} p<0.05$ ( $t$ test).

For the striatum, subdivisions were delimited using criteria previously defined by Yano and Steiner (2005a).

To compensate for background staining and control for variations in illumination level between images, the average pixel density for three regions that lacked labeling was subtracted. An observer blind to the experimental group read each ROI twice. ROI readings were averaged and analyzed using a two-tailed Student's $t$ test. When marginal significance values were obtained, or a parametric test was not appropriate, exploratory statistical analyses were performed using a Wilcoxon signedranks test. Differences were considered significant at $p<0.05$.

Volume of the hilus of the dentate gyrus was calculated using the Cavalieri principle (Severi et al., 2005). For this, a regularly spaced randomly chosen set of sections was labeled for L-Enk throughout the entire rostrocaudal extent of the dentate gyrus. Volume for each section was calculated by multiplying the area of the L-Enk immunoreactivity (-ir) in the hilus by section thickness $(40 \mu \mathrm{m})$ and by sampling interval $(24$ sections). Total volume was determined by adding the volume from all of the sections from the rostrocaudal extent of the dentate gyrus. Data were analyzed using a two-tailed Student's $t$ test with significance at $p<0.05$.

The density of Nissl-labeled cells in the medial prefrontal cortex (mPFC) was determined using the "Grain counting" menu in MCID analysis software (Imaging Research, St. Catharines, Ontario, Canada) on a PC. For this, grayscale images of Nissl sections were converted to binary images, using a threshold that was consistent across images. An oval of equal dimensions for all pictures was drawn using the corpus callosum as an anatomical landmark. The density of Nissl-stained cell bodies was determined by counting grains $(12 \mu \mathrm{m})$ in the marked area. A Student's $t$ test was used to determine significance $(p<0.05)$.

Final photomicrographs were generated from digital images adjusted for levels, brightness, and contrast in Adobe (San Jose, CA) Photoshop 7.0 on a Macintosh G5 computer (Apple, Cupertino, CA). Graphs were prepared with GraphPad Prism 4.01 (GraphPad Software, San Diego CA); quantitative data are represented as average \pm SEM. Images and graphs were assembled into the final figures using Quark (Denver, CO) X-Press 6.1. Statistical analyses were conducted using SPSS for Windows V.11.0.1 (SPSS, Chicago, IL).

\section{Results \\ Developmental MPH administration can influence body weight}

Repeated measures of weight were evaluated for systematic variation by litter and gender, using RMANOVA. In all analyses, the weight by litter interaction was significant, indicating differential rates of weight gain across litters. Thus, litter was entered as a covariate in analyses of between-groups effects.

Within $\sim 1$ week of beginning administration, preweaned rats receiving MPH gained weight at a significantly slower rate than control littermates of the same sex, as evidenced by a significant interaction between weight and administration status $\left(F_{(4,46)}=\right.$ 4.437; $p=0.004$ ) for weight gain analyzed in blocks of $3 \mathrm{~d}$. Also, analysis of weight gained on each individual day from PND10 to PND18 revealed a significant interaction of weight and administration status in which MPHexposed animals gained less weight than matched controls $\left(F_{(8,24)}=2.459 ; p=\right.$ 0.042) (Fig. 1A). Additional analysis of the weight gained in blocks of $3 \mathrm{~d}$ revealed that the MPH-administered rats gained significantly less weight on PND16-PND18 $(p<0.05)$, and a similar trend was observed for PND19-PND21 ( $p=0.1)$. This finding is consistent with clinical data on humans; reduced appetite and weight loss are recognized side effects of MPH treatment (Rapport and Moffitt, 2002).

After weaning on PND21, for the next $11 \mathrm{~d}$, rats receiving MPH continued to gain weight at a significantly slower rate than same-sex control littermates, as evidenced by a significant weight by administration group interaction on RMANOVA $\left(F_{(3,47)}=3.809 ; p=0.016\right)$ on data analyzed in blocks of $3 \mathrm{~d}$. Additional analysis showed that MPH-exposed animals gained weight at a slower rate from PND25 to PND27 $(p<0.05)$ (Fig. $1 B)$.

After discontinuing administration, the rate and magnitude of weight gain was not different between MPH-administered and control rats over the next $35 \mathrm{~d}$ (PND39-PND75). The interaction of weight by administration was not significant $\left(F_{(3,35)}=2.701\right.$; $p>0.05)$. The repeated-measures effect of weight was significant, as all animals continued to gain weight in a linear manner over this period $\left(F_{(3,35)}=399.28 ; p<0.0001\right)$ (Fig. $\left.1 C\right)$.

\section{Developmental MPH administration can influence behavior during adulthood}

The reported effects of MPH on anxiety-like behaviors are mixed. Some studies show decreases (McFadyen-Leussis et al., 2004), and others show increases (Carrey et al., 2000; McFadyen et al., 2002; Bolanos et al., 2003) in anxiety-like behaviors after MPH administration. In the present study, two tests were performed to assess anxiety levels in the male PND135 rats, which received MPH or saline from PND7-PND35 and then were drug-free for 3 months.

\section{Open field}

MPH-administered rats showed a trend toward crossing fewer total lines in the open field compared with controls, but this did not reach statistical significance $(p=0.08)$. There were no differences between MPH-administered and control rats in their latency to enter the center of the open field, number of center squares crossed, or number of rearings. Both groups spent similar amount of time in the squares close to the wall versus the center (control, $293 \pm 2.5 \mathrm{~s} ; \mathrm{MPH}, 290 \pm 3.0 \mathrm{~s} ; p>0.1$ ). However, both groups appeared to spend more time near the walls, sniffing, and with periodic episodes of grooming and rearing. Although standard habituation time (Ramos and Mormede, 1998) was used in this study, a longer test period may have revealed results similar to those observed in the elevated plus-maze.

\section{Elevated plus-maze}

The open-field test may yield confounding results because sometimes anxiety may increase activity, whereas in other cases it may cause freezing behavior (Ramos and Mormede, 1998). Because our results suggested an effect of MPH on anxiety, the elevated 
plus-maze test was used to more specifically assess anxiety. In the elevated plusmaze, MPH-administered rats spent a significantly larger amount of time in the open arms compared with controls [control, $55.03 \pm 4.76 \mathrm{~s}(n=9) ; \mathrm{MPH}, 73.71 \pm$ $\left.6.37 \mathrm{~s}(n=9) ; t_{(16)}=2.35 ; p<0.05\right]$. These changes were not attributable to differences in locomotor activity because $\mathrm{MPH}$-administered rats had a total number of crossings similar to the control group ( $p=0.12)$. These results suggest that 3 months after MPH administration during development, male rats exhibited less anxiety-like behaviors as adults.

\section{Rats that received MPH had neurochemical and cellular differences in brain regions relevant to ADHD}

In male rats administered MPH during development, quantitative differences were identified in four brain regions that have previously been implicated in the etiology of ADHD, learning and attentional processes, and homeostatic regulation: the prefrontal cortex, striatum, hippocampal formation, and hypothalamus. No differences were apparent between control and $\mathrm{MPH}$-administered rats in the other 12 brain regions investigated at either time point after developmental administration of MPH (Table 1).

\section{Medial prefrontal cortex}

The PFC is thought to be a crucial regulator of executive functions and decision making whose proper functioning depends on maintaining a delicate balance of dopamine and norepinephrine activity (Dalley et al., 2004; Arnsten and Li, 2005). This region of the brain receives significant dopamine innervation from ventral tegmental area, and MPH administration has been shown to significantly increase available dopamine in this region while simultaneously improving performance on cognitive tasks in ADHD subjects (Schiffer et al., 2006). In agreement with previous studies (Sesack et al., 1998; Miner et al., 2003), almost no DATimmunoreactive processes were observed in the rat PFC. In control rats assessed at either time point, TH-labeled fibers were diffusely distributed throughout the $\mathrm{MPFC}$, with a slightly greater concentration in layer 6 (Fig. 2A1). At the end of administration (PND35), MPH-administered rats had a significant increase $(55 \%)$ in the density of $\mathrm{TH}$-immunoreactive fibers in layer 6 in the mPFC (Fig. $2 A 2, D)\left(t_{(10)}=2.39 ; p<0.05\right)$. This increase in density of TH-containing fibers tended to remain at PND135, 3 months after cessation of MPH exposure; however, although a striking difference was seen in four pairs of rats, two pairs showed no changes, and the mean difference was not significant (Fig. 2D) $\left(t_{(10)}=1.09 ; p>0.05\right)$. To investigate the possibility that differences in TH density at PND35 correlated with changes in cell distribution and/or number, Nissl staining of the $\mathrm{MPFC}$ was assessed. At PND35, the density of Nissl stained cells was significantly greater $(60 \%)$ in layer 6 of MPH-exposed rats (Fig. 2C,D) $\left(t_{(10)}=2.28 ; p<0.05\right)$. No significant difference in the distribution or number of Nissl-stained cells was observed at the PND135 time point (Fig. $2 D)\left(t_{(10)}=1.31 ; p>0.05\right)$.

Given the observed difference in catecholamines in the mPFC and the reports that MPH can inhibit norepinephrine and serotonin uptake in addition to dopamine uptake (Gatley et al., 1996; Kuczenski and Segal, 2002), labeling for NET, DBH, and SERT was examined. NET-immunoreactive fibers were less abundant than $\mathrm{TH}$-immunoreactive fibers in the $\mathrm{mPFC}$ of control rats (Fig. 2 B1). Quantitative analysis revealed that the number of NETimmunoreactive fibers in the $\mathrm{mPFC}$ was significantly smaller (40\%) in MPH-administered rats at PND35 than in controls (Fig. $2 B 2, D)\left(t_{(10)}=2.25 ; p<0.05\right)$. This MPH-linked difference in NET-ir was not observed in PND135 rats (Fig. $2 D)\left(t_{(4)}=0.266\right.$; $p>0.05)$. Despite the difference observed with NET at PND35, no differences were observed in noradrenergic fibers labeled with $\mathrm{DBH}$ at either time point $\left(\mathrm{PND} 35, t_{(10)}=0.61, p>0.05\right.$; PND135, $\left.t_{(10)}=0.81, p>0.05\right)$. Similarly, no differences were observed in the distribution or density of SERT-immunoreactive fibers in the $\mathrm{mPFC}$ at either $\operatorname{PND} 35\left(t_{(6)}=0.23 ; p>0.05\right)$ or PND135 (Table 1). 


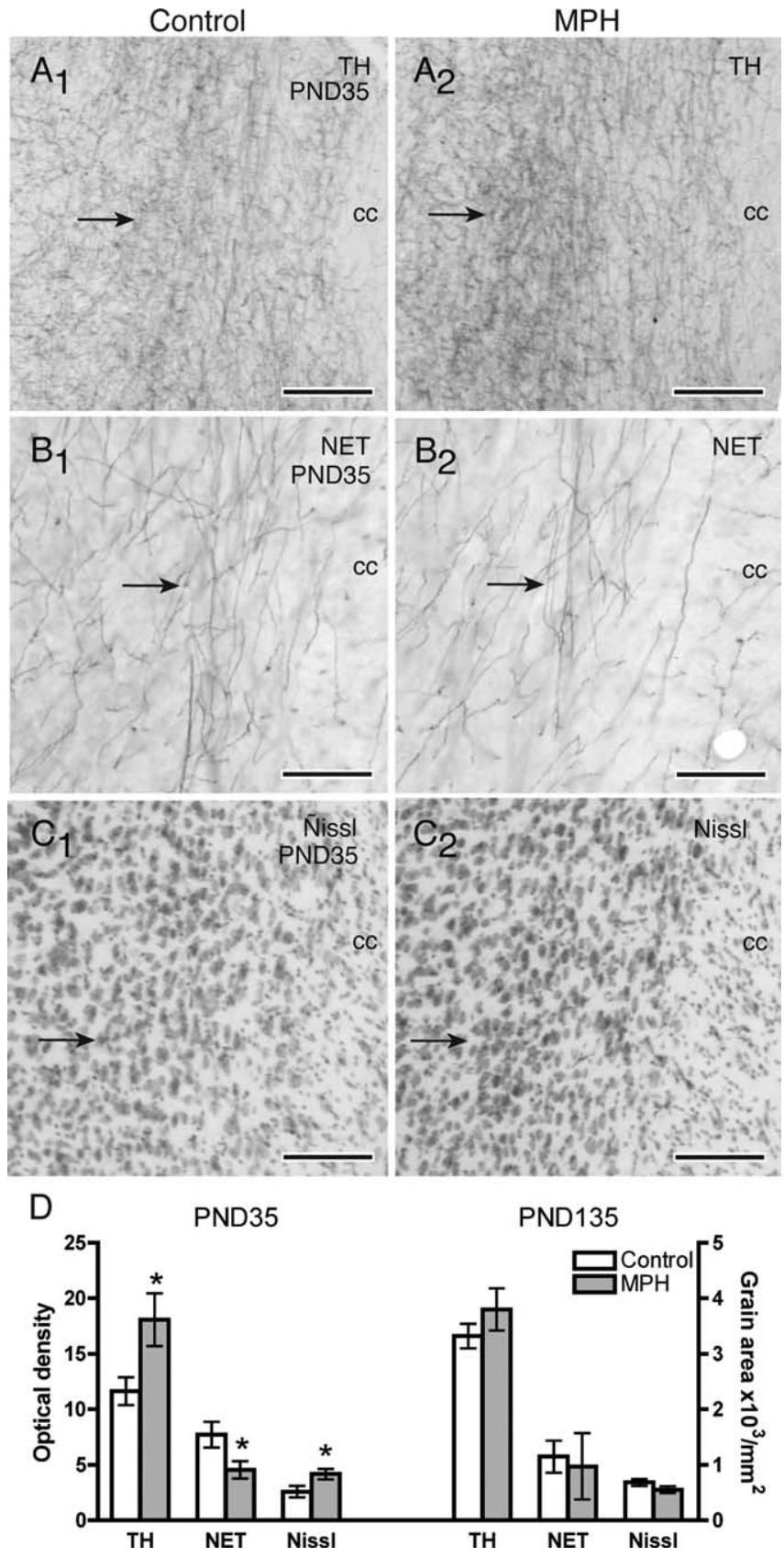

Figure 2. In the $\mathrm{mPFC}$, the distribution of catecholamine fibers and the density of cell bodies were altered immediately after chronic administration of MPH (PND35) but not 3 months later (PND135). A, At PND35, the density of TH-immunoreactive fibers (arrows) is increased in layer 6 of the MPFC of MPH-administered rats (A2) compared with controls (A1). $\boldsymbol{B}$, At PND35, the density of NET-immunoreactive fibers (arrows) decreased in layer 6 of $\mathrm{MPH}$-administered rats (B2) relative to controls (B1). C, At PND35, the density of Nissl-stained cell bodies (arrows) increased in $\mathrm{MPFC}$ layer 6 in MPH-administered rats (C2) compared with controls (C1). Atlas level 9 is shown (AP, $+2.80 \mathrm{~mm}$ from bregma) (Swanson, 1992). cc, Corpus callosum. Scale bars, $100 \mu \mathrm{m}$. D, Comparisons of the density of TH- and NET-immunoreactive fibers (optical density) or Nissl-stained cells (grain area) in layer 6 of the MPFC in control and MPH-exposed rats. At PND35, there was a significant $\left(^{*}\right)$ increase in TH-immunoreactive fiber and Nissl cell density and a significant decrease in NET-labeled fibers in MPH-exposed rats. No differences were seen at PND135. ${ }^{*} p<0.05$ ( $t$ test); $n=6$ rats per condition.

The distribution of cholinergic fibers in the PFC was assessed with VAChT because of the suggested role of the basal forebrain system in learning and memory (Muir, 1997) and our previous findings that cholinergic basal forebrain neurons receive numer- ous inputs from monoamine terminals (Milner, 1991; Milner and Veznedaroglu, 1993). No differences were observed in VAChT-immunoreactive fiber distribution or density in the PFC at either PND35 or PND135 (Table 1).

\section{Striatum}

The striatum is important for the coordination of motor movements and, like the PFC, is rich in dopamine terminals and has been implicated in ADHD (Solanto, 1998; Izenwasser et al., 1999). Previous animal studies have shown that metabolism and dopamine $\mathrm{D}_{2}$ receptor availability are altered in the striatum in response to MPH administration (Volkow et al., 1997). The nucleus accumbens (also known as ventral striatum) is another structure that has been implicated in reinforcement (Nestler, 2001) and is a site for the stimulant actions of MPH (Gerasimov et al., 2000). In control rats from either time point, TH labeling within the striatum was diffuse and interspersed between bundles of the internal capsule and was densest in the dorsal, medial, and ventral subregions (Fig. 3A). Quantitative densitometry revealed that the medial subregion of the striatum showed a $21 \%$ decrease in the density of $\mathrm{TH}$-immunoreactive fibers immediately after $\mathrm{MPH}$ administration (PND35) (Fig. 3B) (Wilcoxon $Z_{(5)}=$ $-2.02 ; p<0.05)$. This difference was not present 3 months after cessation of administration (PND135) (Fig. 3B). The overall pattern of TH or DAT immunoreactivity in the striatum did not appear different in response to $\mathrm{MPH}$ administration at either PND35 or PND135. No significant differences in the density of DAT-immunoreactive processes were observed in any region of the striatum at either PND35 or PND135 (Fig. 3C).

No difference in the density of $\mathrm{TH}$-ir was seen in the caudal nucleus accumbens (where core and shell regions were difficult to separate $)$ at $\operatorname{PND} 35\left(t_{(10)}=-0.15 ; p>0.05\right)$.

\section{Hippocampal formation}

The hippocampal formation is important for learning and memory processes (McGaugh, 2000) and is one of the few sites of ongoing neurogenesis in the adult brain (Gould et al., 2000). Noradrenergic neurons in the locus ceruleus provide a significant input to the hippocampal formation (Loy et al., 1980). Additionally, the hippocampal formation, especially the ventral portion, receives a minor dopamine input from the ventral tegmental area (Gasbarri et al., 1994). To identify catecholaminergic pathways in the hippocampal formation, immunoreactivities to TH, NET, and DBH were localized. In control PND35 and PND135 rats, TH-, NET-, and DBH-immunoreactive fibers were diffusely distributed throughout all hippocampal lamina and were most dense in the hilus of the dentate gyrus (Fig. 4A1,B1) (DBH not shown) and stratum lucidum of region CA3. A significant decrease $(51 \%)$ in the number of NET-labeled fibers was observed in the hilus of MPH-exposed rats at PND35 (Fig. 4B,D). This was seen in both the subgranular zone $\left(t_{(10)}=3.10 ; p=0.01\right)$ and the central hilus $\left(t_{(10)}=2.23 ; p<0.05\right)$. Neither subfield showed this decrease at PND135 (Fig. $4 D$ ) (subgranular zone, $t_{(10)}=0.04$, $p>0.05$; central hilus, $\left.t_{(10)}=0.94, p>0.05\right)$. TH-labeled fiber density was not different at either time point (Fig. $4 A, D$ ) $\left(\mathrm{PND} 35, t_{(10)}=0.06, p>0.05\right.$; PND135, $\left.t_{(10)}=0.19, p>0.05\right)$. Likewise, DBH-labeled fiber density in the dentate hilus was not significantly different in rats given $\mathrm{MPH}$ compared with controls at PND35 $\left(t_{(10)}=0.11 ; p>0.05\right)$ or PND135 $\left(t_{(10)}=0.44 ; p>\right.$ $0.05)$. No differences in the pattern of distribution of TH-, NET-, or DBH-ir were observed in the CA1 or CA3 regions of $\mathrm{MPH}$ administered rats at either PND35 or PND135.

To identify newly born cells in the dentate gyrus, antibodies to 
PSA-NCAM and DCX were used (Francis et al., 1999; Brezun and Daszuta, 2000). PSA-NCAM and DCX primarily identify late neuronal progenitors (Seki and Arai, 1993; Jessberger et al., 2005). At PND35, PSA-NCAM and DCX immunoreactivities in control rats were observed in cell bodies that were evenly distributed throughout the subgranular zone of the dentate gyrus (Fig. 4C1). At the end of the $\mathrm{MPH}$-administration phase (PND35), PSA-NCAM labeling in the medial blade of the subgranular zone of the dentate gyrus extended over a $61 \%$ wider area in $\mathrm{MPH}$-administered rats than in controls (Fig. 4C1,C2) $\left(t_{(10)}=-3.20 ; p=0.009\right)$. Additionally, the hippocampi of MPHadministered rats appeared slightly misshapen in two of six cases (Fig. 4A2). This was unlikely to be caused by mismatched sections, because great care was taken to match rostrocaudal levels. Consistent with other studies of adult rats (Brown et al., 2003), at PND135 PSA-NCAM- or DCXimmunoreactive cell bodies were found in sporadically distributed clusters in the subgranular zone of the dentate gyrus in control rats (data not shown). At PND135, MPH rats were not different from controls in either the lamination or number of PSA-NCAM- or DCX-immunoreactive cells (Table 1) [controls $(n=3), 10.3 \pm 1.0 \mathrm{DCX}$ cells $/ \mathrm{mm}$ of granule cell layer $(\mathrm{gcl})$ length; MPH $(n=3), 10.4 \pm 0.3 \mathrm{DCX}$ cells/mm of gcl length; $t_{(4)}=0.06 ; p>0.05$ ].

In addition to the difference in lamination of PSA-NCAM seen in the present study, other studies have revealed that MPH administration significantly decreases the survival of newly born cells in the dentate gyrus (Lagace et al., 2006). Such changes could affect the hippocampal volume, the number of ectopic cells, and/or lamination, and thus these parameters were evaluated. The total volume of the dentate hilar region of $\mathrm{MPH}-$ administered and control rats was assessed using immunoreactivity for L-Enk. In agreement with previous studies (Gall et al., 1981; Commons and Milner, 1995), L-Enk immunoreactivity delineated the hilus of the dentate gyrus. The hilar volume was not significantly different at PND35 $\left(t_{(10)}=0.31 ; p>0.05\right)$ or at $\operatorname{PND} 135\left(t_{(10)}=0.627 ; p>0.5\right)$. To determine whether the number of ectopic cells in the dentate hilar region was altered after MPH exposure, sections were labeled with PROX1. At both the PND35 and PND135 time points, no significant differences in the numbers of PROX1-labeled nuclei in the hilus were found $\left(\mathrm{PND} 35, t_{(10)}=0.53, p>0.05 ; \mathrm{PND} 135, t_{(14)}=0.15, p>0.05\right)$. The lamination pattern of dentate gyrus was assessed with calbindin (which delineates the molecular layer, granule cell layer, and hilus), and the distribution of astroglia in the dentate gyrus was assessed using GFAP. Neither the calbindin nor GFAP staining patterns appeared different between the two groups at either PND35 or PND135 (Table 1).

\section{Hypothalamus}

Given the changes in weight observed with MPH administration and the involvement of NPY in appetite, arousal, and autonomic regulation (Fu et al., 2004; Kishi et al., 2005), NPY-ir was exam-
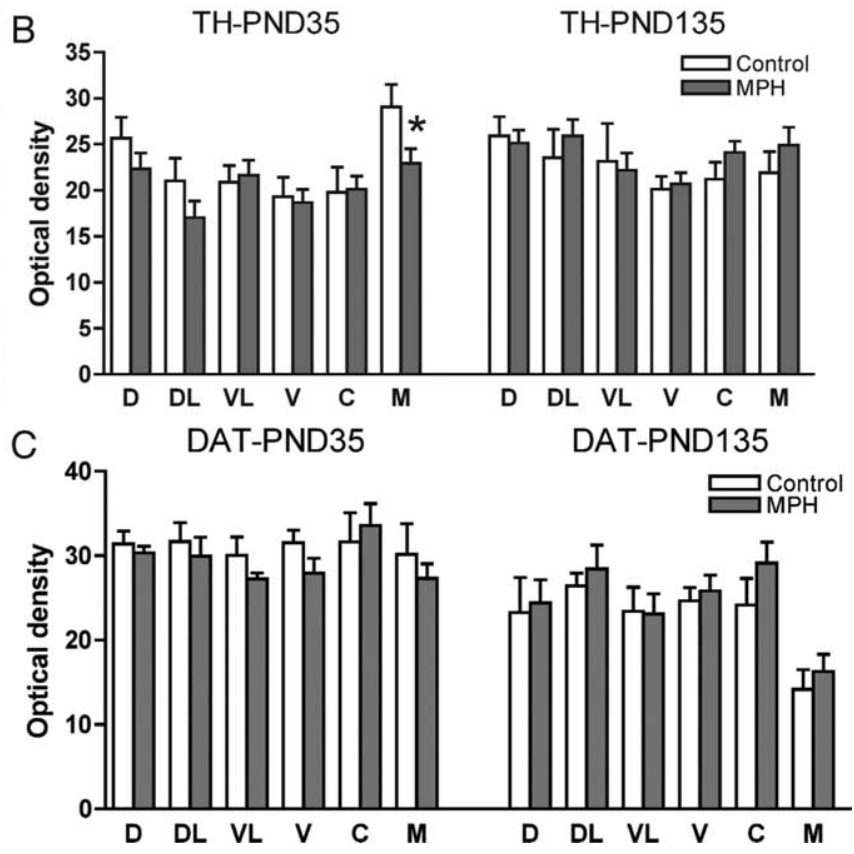

Figure 3. TH immunoreactivity was reduced in the medial striatum immediately after chronic MPH administration (PND35) (PND135). A, TH-ir in a coronal section of striatum [atlas level 16; AP, $+0.10 \mathrm{~mm}$ from bregma (Swanson, MPH group. $C$, The density of DAT-immunoreactive fibers was similar in MPH-administered and control rats at both time st); $n=6$ rats per group. Scale bar, $1 \mathrm{~mm}$.

ined in two regions of the hypothalamus, the PVN and the DMH. In control rats at either PND35 or PND135, dense NPY-ir was found in the PVN (especially the medial parvocellular part) and the posterior region of the DMH (Fig. 5A1,B1). In MPHadministered rats at PND35, the density of NPY-immunoreactive fibers in the PVN was significantly higher (10\%) than in controls (Fig. 5A2,C) (Wilcoxon $Z_{(5)}=-2.20 ; p<0.05$ ). In the DMH, the distribution of NPY-immunoreactive fibers was more widespread in MPH-exposed rats at PND35 (Fig. 5B2,C), although there was considerable variability between $\mathrm{MPH}$ rats, and the density of NPY-labeled fibers in the central DMH did not attain significant difference (Wilcoxon $Z_{(5)}=-1.36$; $p=0.08$ ). No differences in NPY-immunoreactive fiber density or distribution were observed between the MPH group and the control group at PND135 in either the PVN (Wilcoxon $Z_{(5)}=-0.31 ; p>0.05$ ) or the DMH (Wilcoxon $Z_{(5)}=-0.734 ; p>0.05$ ).

\section{Other observations}

No gross cytoarchitectural differences were observed between the groups at either time point, with the exception of one MPH rat from the PND35 group. This rat had an enlarged rostral lateral ventricle on one side of the forebrain (Swanson levels 13-21; data not shown). Sections through this region were excluded from later analysis.

Several other monoamine-rich regions were examined. Dopaminergic neurons in the substantia nigra and ventral tegmental area innervate the striatum and nucleus accumbens, respectively (Heimer et al., 1995). Consistent with previous studies (Fallon and Loughlin, 1987), TH-immunoreactive neurons were particularly dense in the pars compacta of the substantia nigra $(\mathrm{SNc})$ and in the parabrachial (PBP) and paranigral (PN) subdivisions 
Control
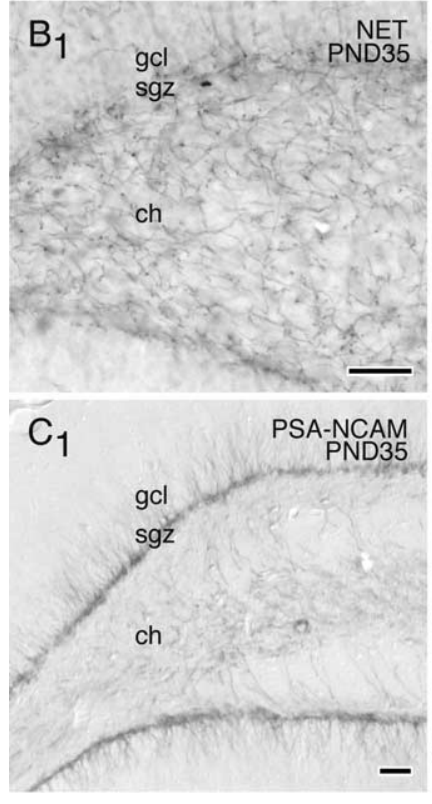

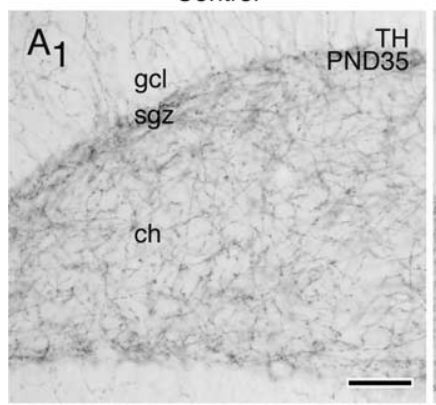

MPH
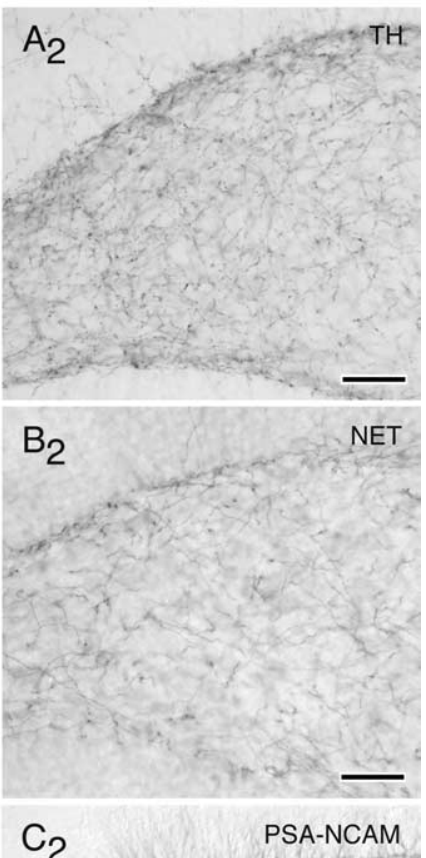

$\mathrm{C}_{2}$

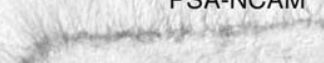

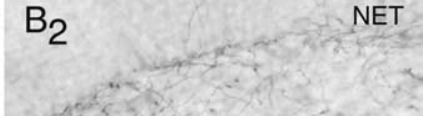

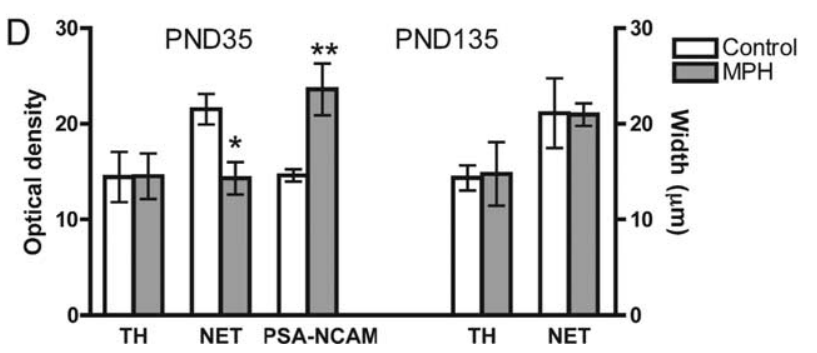

Figure 4. In the dentate gyrus, fibers immunoreactive for NET, but not for TH, were reduced in density, and the distribution of new cells was altered immediately after chronic MPH administration (PND35). $\boldsymbol{A}$, Controls (A1) and MPH-administered rats (A2) had similar densities of TH-labeled fibers in the central hilus (ch) immediately after chronic administration (PND35). $\boldsymbol{B}$, A decrease in the density of NET-immunoreactive fibers in the central hilus was observed in PND35 rats given chronic MPH (B2) compared with controls (B1). C, The laminar distribution of new cells indicated by PSA-NCAM labeling ( $\mathbf{C}$, arrows) was expanded in the subgranular zone (sgz) of the ventral blade in MPH-administered rats at PND35 (C2) compared with controls (C1). Atlas level 32 is shown (AP, $-3.90 \mathrm{~mm}$ from bregma) (Swanson, 1992). Scale bars, $100 \mu \mathrm{m} . \boldsymbol{D}$, Comparison of the density of TH and NET fibers and the width of PSA-NCAM labeling in the subgranular zone of the hilus of the dentate gyrus in control and MPH-exposed rats. A significant decrease in NET-labeled fibers ${ }^{*}$ ) and a significant increase in the width of PSA-NCAM labeling $\left({ }^{* *}\right)$ were seen in MPH-administered rats at PND35. The density of TH-labeled fibers was not different at either time point. ${ }^{*} p<0.05 ;{ }^{* *} p<0.01$ ( $t$ test); $n=6$ per condition.

of the ventral tegmental area. No significant differences were found in the density of TH-ir in any of these subdivisions between $\mathrm{MPH}$-administered and control rats at PND35 $\left(\mathrm{SNc}, t_{(10)}=1.1\right.$, $p>0.05 ; \mathrm{PN}, t_{(10)}=-0.62, p>0.05 ; \mathrm{PBP}, t_{(10)}=-0.53, p>$ $0.05)$ or PND135 (SNc, $t_{(10)}=0.35, p>0.05 ; \mathrm{PN}, t_{(10)}=1.26$, $p>0.05$; PBP, $\left.t_{(10)}=-0.15, p>0.05\right)$.

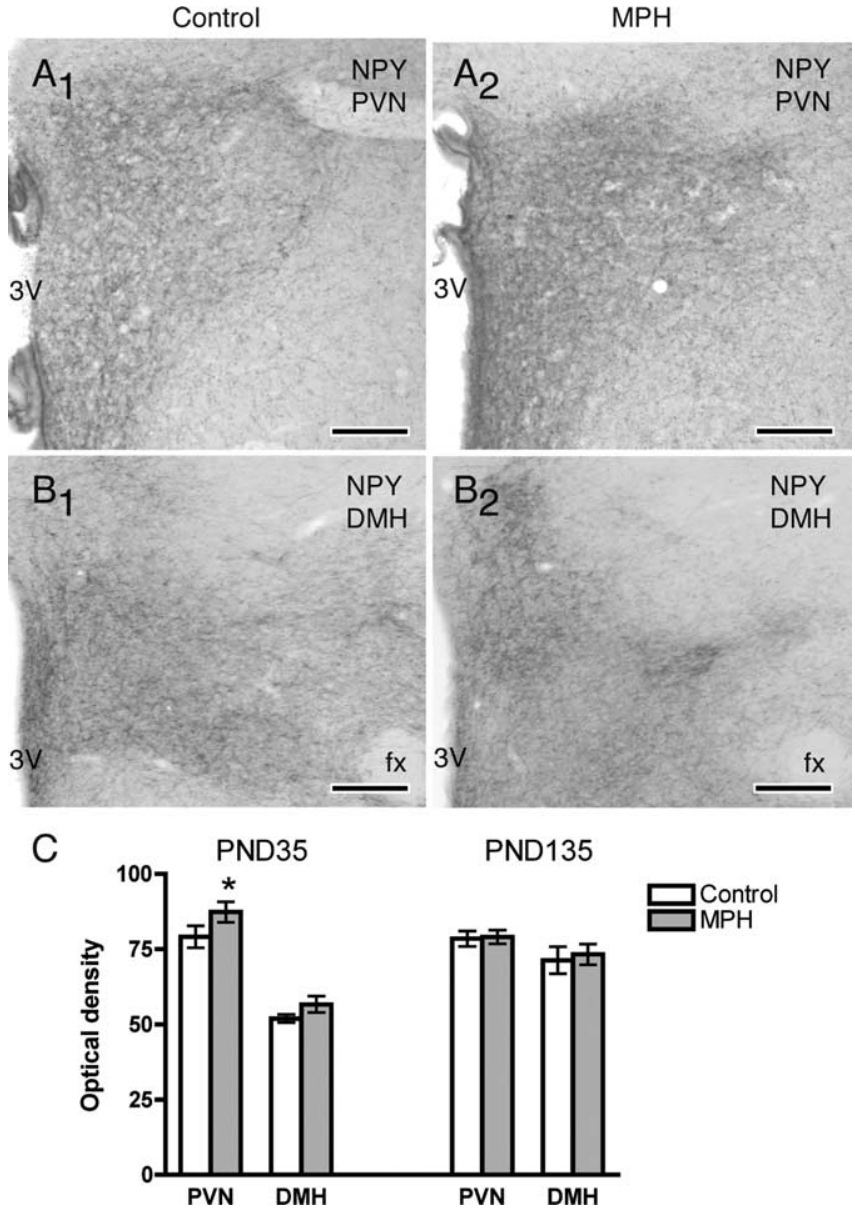

Figure 5. In the hypothalamus, the density of NPY-ir in the PVN and DMH increased with MPH administration (PND35). $\boldsymbol{A}$, At PND35, increases in the density of NPY-immunoreactive fibers in the PVN were seen in MPH-administered rats (A2) compared with controls (A1). $\boldsymbol{B}$, In the DMH, MPH-administered rats (B2) showed a more widespread distribution of NPY-labeled fibers than controls (B1). Atlas levels 26 (AP, $-1.78 \mathrm{~mm}$ from bregma; $\boldsymbol{A 1}, \boldsymbol{A 2}$ ) and 30 (AP, $-3.25 \mathrm{~mm}$ from bregma; $\boldsymbol{B 1}$, B2) are shown (Swanson, 1992). 3V, Third ventricle; fx, fornix. Scale bars, $500 \mu \mathrm{m}$. C, Comparisons of the density of NPY-immunoreactive fibers in the PVN and DMH in control and MPH-exposed rats at PND35 and PND135. A significant $\left(^{*}\right)$ increase in NPY-labeled fibers was seen in MPH-administered rats at PND35. ${ }^{*} p<0.05$ (Wilcoxon test); $n=6$ rats per condition.

\section{Discussion}

This study reveals that prolonged developmental exposure to high therapeutic doses of MPH has short-term effects on several neurotransmitter systems in the rat $\mathrm{mPFC}$, striatum, hippocampus, and hypothalamus and few long-term effects. These MPHinduced changes may contribute to our observed alterations in weight and anxiety behavior and suggest modifications of specific brain regions that may be involved in the therapeutic and accessory actions of $\mathrm{MPH}$ in ADHD treatment.

\section{Developmental MPH alters catecholamine fiber and cell density in $\mathrm{mPFC}$}

The increase in $\mathrm{TH}$-immunoreactive fiber density in the mPFC of $\mathrm{MPH}$-administered rats at PND35 suggests that MPH boosts catecholamines in this region and complements previous findings (see Introduction). The trend toward redistribution of $\mathrm{TH}$-ir processes at PND135 suggests that morphological changes in catecholamine fibers may remain well into adulthood. Although the immunoreactivity for $\mathrm{TH}$ increased after $\mathrm{MPH}$ exposure, that for $\mathrm{DBH}$ (the enzyme that converts dopamine to noradrenaline) was 
unchanged, suggesting either that the TH enzyme is selectively sensitive to MPH exposure or perhaps that a subset of the catecholaminergic fibers (e.g., dopaminergic) were affected. An accumulation of TH-immunoreactive fibers in deep mPFC layers in MPH-administered rats resembled the gathered catecholamine fibers present in normal immature cortex (Berger et al., 1985), suggesting that MPH may delay developmental processes in the mPFC. Consistent with this idea, MPH-administered rats had more Nissl-stained cells in deep cortical layers, where the early postmitotic neurons collect (Kriegstein and Noctor, 2004).

The altered distribution of cells and catecholamine fibers at PND35 may disrupt the normal maturation of other components of the mPFC. Catecholamine terminals in PFC innervate pyramidal cells (Krimer et al., 1997) and, to a lesser extent, GABAergic interneurons (Sesack et al., 1995). Catecholaminergic innervation of pyramidal cells matures gradually postnatally, whereas that of interneurons remains stable (Lambe et al., 2000). Developmental exposure to other psychostimulants alters dendritic morphology of PFC pyramidal cells and diminishes certain GABAergic interneuron populations (Robinson and Kolb, 1999; Morrow et al., 2005). Similarly, MPH exposure during the construction of catecholaminergic connections to excitatory mPFC neurons may disturb the normal development of mPFC circuitry or morphology.

At PND35, NET-immunoreactive processes were fewer in the $\mathrm{MPH}$-exposed rats. The present immunolabeling conditions favored detection of cytosolic NET, because the use of detergents can dissolve membranes containing plasmalemmal NET; NET is primarily cytosolic under resting conditions but redistributes to the plasmalemma with certain stimuli (Miner et al., 2003, 2006). Because dopamine is the preferred substrate for NET and can be taken up by noradrenergic PFC axons (Sesack et al., 1998), NET may have moved to the plasmalemma in response to MPHinduced dopamine increases. Alternatively, NET may have been downregulated in response to elevated extracellular dopamine and/or norepinephrine after chronic MPH administration.

\section{Developmental MPH alters dopaminergic fibers in the striatum}

A decrease in dopaminergic fibers, identified by $\mathrm{TH}$, was seen in medial striatum with MPH administration (PND35). These observations are consistent with the findings that acute MPH administration induces changes in striatal transcription factors (cFos, zif268), genes that regulate synaptic plasticity (Homer1a), and substance P (in striatonigral outputs) (Yano and Steiner, 2005a,b). Moreover, these MPH-induced effects occur primarily through a dopaminergic mechanism, because they are inhibited by blocking striatal $D_{1}$ receptors (Yano et al., 2006). The medial striatum receives excitatory inputs from the anterior cingulate cortex and prelimbic PFC (Berendse et al., 1992; Willuhn et al., 2003), suggesting that chronic MPH specifically targets corticostriatal circuits that are involved in sensorimotor functions.

$\mathrm{TH}$-ir decreased in the striatum but increased in the mPFC with MPH administration. Several differences in dopaminergic transmission between the two regions may contribute to these opposite responses. The striatum and $\mathrm{mPFC}$ are innervated by separate populations of dopamine neurons from substantia nigra and ventral tegmental area, respectively (Berger et al., 1991). The striatum contains abundant DAT, whereas the mPFC contains almost none (Sesack et al., 1998). Moreover, in striatum, dopamine is primarily taken up by DAT at synaptic release sites, whereas in $\mathrm{mPFC}$, dopamine uptake involves NET on nearby norepinephrine terminals or, to a lesser extent, DAT on preter- minal dopaminergic axons (Sesack et al., 1998; Miner et al., 2003).

\section{Developmental MPH alters catecholamine fibers and morphology in dentate gyrus}

At PND35, MPH-exposed rats showed decreased density of NETimmunoreactive fibers, but not TH-labeled fibers, in the dentate hilus. No differences were observed at PND135. The decrease in NET-ir is consistent with the decreases in NET-labeled fibers seen in the mPFC and may occur for the reasons discussed above. The change in NET fiber density is probably not caused by shrinkage or expansion of the dentate gyrus, because no volume changes were found. $\mathrm{TH}$ is almost exclusively in noradrenergic fibers in the dentate gyrus and labels nearly the identical population of fibers identified by DBH (Milner and Bacon, 1989). Thus, the lack of change in $\mathrm{TH}$-ir in the dentate gyrus is similar to the lack of change in DBH-ir in the mPFC; both suggest stability of afferents carrying norepinephrine.

The lamination of new cells in the dentate gyrus showed subtle differences in the MPH-exposed rats at PND35. The subgranular zone is the last portion of the dentate to mature (Bayer et al., 1993), and it is possible that its maturation is delayed in young rats exposed to $\mathrm{MPH}$, producing less restricted distribution of new cells. Consistent with this possibility, new-cell markers have a wider distribution in younger rat hilus (Herrick et al., 2006). The new-cell lamination difference was not observed in the adults (PND135), nor was there a difference in the number of new cells or total volume in the adults. This agrees with other findings that developmental exposure to MPH does not alter new-cell proliferation in adults (Lagace et al., 2006); however, when considering the functional implications of juvenile MPH exposure, it is important to note that long-term survival of newly born dentate cells was diminished in adults (Lagace et al., 2006).

\section{Developmental MPH alters hypothalamic NPY density}

Rats that received MPH showed increased NPY-ir in the hypothalamic PVN and a redistribution of NPY-ir in the DMH at PND35. NPY-ir was normal in distribution and density in both regions at PND135. Based on our previous findings (Pierce et al., 1999), the increase in NPY density likely reflects an increase in NPY labeling associated with dense-core vesicles, the storage sites of peptides. Alternatively, the increase in NPY density may reflect a concentration of NPY fibers in a smaller area. Regardless, our results are consistent with observations that NPY systems in hypothalamus and other brain areas are responsive to dopaminealtering psychostimulant drugs and other stimuli (Lewis et al., 1993; Westwood and Hanson, 1999; D’Este et al., 2006). Similarly, NPY induction of the stress hormone corticotrophinreleasing factor (CRF) is regulated by catecholamines (Haas and George, 1989).

MPH-induced changes in PVN and DMH likely affect several autonomic functions and may have contributed to the observed changes in weight and anxiety behavior. PVN neurons, including those containing CRF, are reciprocally connected with cardiovascular-regulating medullary neurons (Milner et al., 1993; Hermes et al., 2006). PVN neurons regulate medullary catecholamine responses to stress (Dayas et al., 2004) through a mechanism involving the mPFC (Spencer et al., 2005). DMH neurons project to the PVN and are involved in regulating weight and the expression of food-entrainable circadian rhythms (Bellinger and Bernardis, 2002; Gooley et al., 2006). Increased NPY levels have been correlated with weight gain (Bellinger and Ber- 
nardis, 2002), and our observed increases in NPY may reflect compensatory responses to MPH exposure.

\section{Developmental MPH affects adult anxiety behavior}

Three months after administration (PND135), MPH-exposed rats entered and spent more time in the open arms of the elevated plus-maze, suggesting that MPH reduced anxiety-like behaviors. Consistent with our results, $2 \mathrm{mg} / \mathrm{kg} \mathrm{MPH}$ administered to mice during early adolescence increased the time spent in open arms of the elevated plus-maze as adults (Bolanos et al., 2003), whereas administration of $5 \mathrm{mg} / \mathrm{kg} \mathrm{MPH}$ to mice prenatally produced the opposite effect (McFadyen-Leussis et al., 2004). Together, the findings suggest that exposure to MPH during earlier developmental periods, when synaptogenesis is still actively occurring (Bayer et al., 1993), might render animals less susceptible to anxiety-like behaviors in adulthood.

\section{Conclusion}

This study provides novel anatomical evidence that therapeutic doses of MPH chronically administered to normal juvenile rats results in short-term changes in four brain areas involved in motivated behaviors, cognition, appetite, and stress. These changes were mirrored by differences in weight gain and anxiety. No significant long-term changes in chemical neuroanatomy were seen, although a trend toward persistent differences in mPFC suggests that additional study may be important. Our findings are consistent with the views that MPH targets brain regions beyond those implicated in executive function in children with ADHD (Castellanos et al., 2006) and that the duration and timing of $\mathrm{MPH}$ treatment are important variables affecting cognitive and neural functions. This study also suggests regions of interest for future functional neuroimaging studies and clinical investigations. Moreover, these results suggest that although the observed neuroanatomical changes largely resolve with time, chronic modulation of young brains with MPH may exert effects on brain neurochemistry that modify some behaviors in adulthood.

\section{References}

Angold A, Erkanli A, Egger HL, Costello EJ (2000) Stimulant treatment for children: a community perspective. J Am Acad Child Adolesc Psychiatry 39:975-984.

Arnsten AF, Li BM (2005) Neurobiology of executive functions: catecholamine influences on prefrontal cortical functions. Biol Psychiatry 57:1377-1384.

Arvidsson U, Riedl M, Elde R, Meister B (1997) Vesicular acetylcholine transporter (VAChT) protein: a novel and unique marker for cholinergic neurons in the central and peripheral nervous systems. J Comp Neurol 378:454-467.

Barone Jr S, Das KP, Lassiter TL, White LD (2000) Vulnerable processes of nervous system development: a review of markers and methods. Neurotoxicology 21:15-36.

Bayer SA, Altman J, Russo RJ, Zhang X (1993) Timetables of neurogenesis in the human brain based on experimentally induced patterns in the rat. Neurotoxicology 14:83-144.

Bellinger LL, Bernardis LL (2002) The dorsomedial hypothalamic nucleus and its role in ingestive behavior and body weight regulation: lessons learned from lesioning studies. Physiol Behav 76:431-442.

Berendse HW, Galis-de Graaf Y, Groenewegen HJ (1992) Topographical organization and relationship with ventral striatal compartments of prefrontal corticostriatal projections in the rat. J Comp Neurol 316:314-347.

Berger B, Verney C, Febvret A, Vigny A, Helle KB (1985) Postnatal ontogenesis of the dopaminergic innervation in the rat anterior cingulate cortex (area 24). Immunocytochemical and catecholamine fluorescence histochemical analysis. Brain Res 353:31-47.

Berger B, Gaspar P, Verney C (1991) Dopaminergic innervation of the cerebral cortex: unexpected differences between rodents and primates. Trends Neurosci 14:21-27.
Bolanos CA, Barrot M, Berton O, Wallace-Black D, Nestler EJ (2003) Methylphenidate treatment during pre- and periadolescence alters behavioral responses to emotional stimuli at adulthood. Biol Psychiatry 54:1317-1329.

Brake WG, Sullivan RM, Flores G, Srivastava LK, Gratton A (1999) Neonatal ventral hippocampal lesions attenuate the nucleus accumbens dopamine response to stress: an electrochemical study in the adult rat. Brain Res 831:25-32.

Brezun JM, Daszuta A (2000) Serotonergic reinnervation reverses lesioninduced decreases in PSA-NCAM labeling and proliferation of hippocampal cells in adult rats. Hippocampus 10:37-46.

Brown JP, Couillard-Despres S, Cooper-Kuhn CM, Winkler J, Aigner L, Kuhn HG (2003) Transient expression of doublecortin during adult neurogenesis. J Comp Neurol 467:1-10.

Brown P, Molliver ME (2000) Dual serotonin (5-HT) projections to the nucleus accumbens core and shell: relation of the 5-HT transporter to amphetamine-induced neurotoxicity. J Neurosci 20:1952-1963.

Carrey N, McFadyen MP, Brown RE (2000) Effects of subchronic methylphenidate hydrochloride administration on the locomotor and exploratory behavior of prepubertal mice. J Child Adolesc Psychopharmacol 10:277-286.

Castellanos FX, Sonuga-Barke EJ, Milham MP, Tannock R (2006) Characterizing cognition in ADHD: beyond executive dysfunction. Trends Cogn Sci 10:117-123.

Chang PC, Aicher SA, Drake CT (2000) Kappa opioid receptors in rat spinal cord vary across the estrous cycle. Brain Res 861:168-172.

Commons KG, Milner TA (1995) Ultrastructural heterogeneity of enkephalin-containing neurons in the rat hippocampal formation. J Comp Neurol 358:324-342.

Dalley JW, Cardinal RN, Robbins TW (2004) Prefrontal executive and cognitive functions in rodents: neural and neurochemical substrates. Neurosci Biobehav Rev 28:771-784.

Dayas CV, Buller KM, Day TA (2004) Hypothalamic paraventricular nucleus neurons regulate medullary catecholamine cell responses to restraint stress. J Comp Neurol 478:22-34.

D’Este L, Casini A, Pontieri FE, Renda TG (2006) Changes in neuropeptide FF and NPY immunohistochemical patterns in rat brain under heroin treatment. Brain Res 1083:151-158.

Dobbing J, Sands J (2000) Comparative aspects of brain growth spurt. Early Hum Dev 3:79-83.

Drake CT, Chang PC, Harris JA, Milner TA (2002) Neurons with mu opioid receptors interact indirectly with enkephalin-containing neurons in the rat dentate gyrus. Exp Neurol 176:254-261.

Elliott RC, Khademi S, Pleasure SJ, Parent JM, Lowenstein DH (2001) Differential regulation of basic helix-loop-helix mRNAs in the dentate gyrus following status epilepticus. Neuroscience 106:79-88.

Fallon JH, Loughlin SE (1987) Monoamine innervation of cerebral cortex and a theory of the role of monoamines in cerebral cortex and basal ganglia. In: Cerebral cortex, Vol 6 (Jones EG, Peters A, eds), pp 41-127. New York: Plenum.

Faraj BA, Israili ZH, Perel JM, Jenkins ML, Holtzman SG, Cucinell SA, Dayton PG (1974) Metabolism and disposition of methylphenidate-14C: studies in man and animals. J Pharmacol Exp Ther 191:535-547.

Francis F, Koulakoff A, Boucher D, Chafey P, Schaar B, Vinet MC, Friocourt G, McDonnell N, Reiner O, Kahn A, McConnell SK, Berwald-Netter Y, Denoulet P, Chelly J (1999) Doublecortin is a developmentally regulated, microtubule-associated protein expressed in migrating and differentiating neurons. Neuron 23:247-256.

Fu LY, Acuna-Goycolea C, van den Pol AN (2004) Neuropeptide Y inhibits hypocretin/orexin neurons by multiple presynaptic and postsynaptic mechanisms: tonic depression of the hypothalamic arousal system. J Neurosci 24:8741-8751.

Gall C, Brecha N, Karten HJ, Chang KJ (1981) Localization of enkephalinlike immunoreactivity to identified axonal and neuronal populations of the rat hippocampus. J Comp Neurol 198:335-350.

Gasbarri A, Verney C, Innocenzi R, Campana E, Pacitti C (1994) Mesolimbic dopaminergic neurons innervating the hippocampal formation in the rat: a combined retrograde tracing and immunohistochemical study. Brain Res 668:71-79.

Gatley SJ, Pan D, Chen R, Chaturvedi G, Ding YS (1996) Affinities of methylphenidate derivatives for dopamine, norepinephrine and serotonin transporters. Life Sci 58:231-239. 
Gerasimov MR, Franceschi M, Volkow ND, Gifford A, Gatley SJ, Marsteller D, Molina PE, Dewey SL (2000) Comparison between intraperitoneal and oral methylphenidate administration: a microdialysis and locomotor activity study. J Pharmacol Exp Ther 295:51-57.

Gooley JJ, Schomer A, Saper CB (2006) The dorsomedial hypothalamic nucleus is critical for the expression of food-entrainable circadian rhythms. Nat Neurosci 9:398-407.

Gordon N (1999) Attention deficit hyperactivity disorder: possible causes and treatment. Int J Clin Pract 53:524-528.

Gould E, Tanapat P, Rydel T, Hastings N (2000) Regulation of hippocampal neurogenesis in adulthood. Biol Psychiatry 48:715-720.

Grund T, Lehmann K, Bock N, Rothenberger A, Teuchert-Noodt G (2006) Influence of methylphenidate on brain development-an update of recent animal experiments. Behav Brain Funct 2:2.

Haas DA, George SR (1989) Neuropeptide Y-induced effects on hypothalamic corticotropin-releasing factor content and release are dependent on noradrenergic/adrenergic neurotransmission. Brain Res 498:333-338.

Hechtman L (2006) Long-term treatment of children and adolescents with attention-deficit/hyperactivity disorder (ADHD). Curr Psychiatry Rep 8:398-408.

Heimer L, Zahm DS, Alheid GF (1995) Basal ganglia. In: The rat nervous system (Paxinos G, ed), pp 579-628. San Diego: Academic.

Hermes SM, Mitchell JL, Aicher SA (2006) Most neurons in the nucleus tractus solitarii do not send collateral projections to multiple autonomic targets in the rat brain. Exp Neurol 198:539-551.

Herrick SP, Waters EM, Drake CT, McEwen BS, Milner TA (2006) Extranuclear estrogen receptor beta immunoreactivity is on doublecortincontaining cells in the adult and neonatal rat dentate gyrus. Brain Res 1121:46-58.

Hsu SM, Raine L, Fanger H (1981) Use of avidin-biotin-peroxidase complex $(A B C)$ in immunoperoxidase techniques: a comparison between $\mathrm{ABC}$ and unlabeled antibody (PAP) procedures. J Histochem Cytochem 29:557-580.

Izenwasser S, Coy AE, Ladenheim B, Loeloff RJ, Cadet JL, French D (1999) Chronic methylphenidate alters locomotor activity and dopamine transporters differently from cocaine. Eur J Pharmacol 373:187-193.

Jensen PS, Bhatara VS, Vitiello B, Hoagwood K, Feil M, Burke LB (1999) Psychoactive medication prescribing practices for U.S. children: gaps between research and clinical practice. J Am Acad Child Adolesc Psychiatry 38:557-565.

Jessberger S, Romer B, Babu H, Kempermann G (2005) Seizures induce proliferation and dispersion of doublecortin-positive hippocampal progenitor cells. Exp Neurol 196:342-351.

Joh TH, Ross ME (1983) Preparation of catecholamine synthesizing enzymes as immunogen for immunocytochemistry. In: Immunocytochemistry (Cuello AC, ed), pp 121-138. New York: Wiley.

Jones SP, Rahimi O, O’Boyle MP, Diaz DL, Claiborne BJ (2003) Maturation of granule cell dendrites after mossy fiber arrival in hippocampal field CA3. Hippocampus 13:413-427.

Kishi T, Aschkenasi CJ, Choi BJ, Lopez ME, Lee CE, Liu H, Hollenberg AN, Friedman JM, Elmquist JK (2005) Neuropeptide Y Y1 receptor mRNA in rodent brain: distribution and colocalization with melanocortin-4 receptor. J Comp Neurol 482:217-243.

Klintsova AY, Greenough WT (1999) Synaptic plasticity in cortical systems. Curr Opin Neurobiol 9:203-208.

Kriegstein AR, Noctor SC (2004) Patterns of neuronal migration in the embryonic cortex. Trends Neurosci 27:392-399.

Krimer LS, Jakab RL, Goldman-Rakic PS (1997) Quantitative threedimensional analysis of the catecholaminergic innervation of identified neurons in the macaque prefrontal cortex. J Neurosci 17:7450-7461.

Kuczenski R, Segal DS (1997) Effects of methylphenidate on extracellular dopamine, serotonin, and norepinephrine: comparison with amphetamine. J Neurochem [Erratum (1997) 69:1332] 68:2032-2037.

Kuczenski R, Segal DS (2002) Exposure of adolescent rats to oral methylphenidate: preferential effects on extracellular norepinephrine and absence of sensitization and cross-sensitization to methamphetamine. J Neurosci 22:7264-7271.

Lagace DC, Yee JK, Bolanos CA, Eisch AJ (2006) Juvenile administration of methylphenidate attenuates adult hippocampal neurogenesis. Biol Psychiatry 60:1121-1130.

Lambe EK, Krimer LS, Goldman-Rakic PS (2000) Differential postnatal de- velopment of catecholamine and serotonin inputs to identified neurons in prefrontal cortex of rhesus monkey. J Neurosci 20:8780-8787.

Levitt P, Harvey JA, Friedman E, Simansky K., Murphy EH (1997) New evidence for neurotransmitter involvement in brain development. Trends Neurosci 20:269-274.

Lewis DE, Shellard L, Koeslag DG, Boer DE, McCarthy HD, McKibbin PE, Russell JC, Williams G (1993) Intense exercise and food restriction cause similar hypothalamic neuropeptide $\mathrm{Y}$ increases in rats. Am J Physiol 264:E279-E284.

Loy R, Koziell JD, Lindsay JD, Moore RY (1980) Noradrenergic innervation of the adult rat hippocampal formation. J Comp Neurol 189:699-710.

Marshall E (2000) Duke study faults overuse of stimulants for children. Science 289:721.

McFadyen MP, Brown RE, Carrey N (2002) Subchronic methylphenidate administration has no effect on locomotion, emotional behavior, or water maze learning in prepubertal mice. Dev Psychobiol 41:123-132.

McFadyen-Leussis MP, Lewis SP, Bond TL, Carrey N, Brown RE (2004) Prenatal exposure to methylphenidate hydrochloride decreases anxiety and increases exploration in mice. Pharmacol Biochem Behav 77:491-500.

McGaugh JL (2000) Memory-a century of consolidation. Science 287:248-251.

Milner TA (1991) Cholinergic neurons in the rat septal complex: ultrastructural characterization and synaptic relations with catecholaminergic terminals. J Comp Neurol 314:37-54.

Milner TA, Bacon CE (1989) Ultrastructural localization of tyrosine hydroxylase-like immunoreactivity in the rat hippocampal formation. J Comp Neurol 281:479-495.

Milner TA, Veznedaroglu E (1992) Ultrastructural localization of neuropeptide Y-like immunoreactivity in the rat hippocampal formation. Hippocampus 2:107-126.

Milner TA, Veznedaroglu E (1993) Serotonin-containing terminals synapse on septohippocampal neurons in the rat. J Neurosci Res 36:260-271.

Milner TA, Reis DJ, Pickel VM, Aicher SA, Giuliano R (1993) Ultrastructural localization and neuroanatomical origins of corticotropin-releasing factor in the rat rostral ventrolateral medulla: implications for central cardiovascular regulation. J Comp Neurol 333:151-167.

Milner TA, Wiley RG, Kurucz OS, Prince SR, Pierce JP (1997) Selective changes in hippocampal neuropeptide $\mathrm{Y}$ neurons following removal of the cholinergic septal inputs. J Comp Neurol 386:46-59.

Milner TA, Rosin DL, Lee A, Aicher SA (1999) Alpha2A-adrenergic receptors are primarily presynaptic heteroreceptors in the $\mathrm{C} 1$ area of the rat rostral ventrolateral medulla. Brain Res 821:200-211.

Miner LH, Schroeter S, Blakely RD, Sesack SR (2003) Ultrastructural localization of the norepinephrine transporter in superficial and deep layers of the rat prelimbic prefrontal cortex and its spatial relationship to probable dopamine terminals. J Comp Neurol 466:478-494.

Miner LH, Jedema HP, Moore FW, Blakely RD, Grace AA, Sesack SR (2006) Chronic stress increases the plasmalemmal distribution of the norepinephrine transporter and the coexpression of tyrosine hydroxylase in norepinephrine axons in the prefrontal cortex. J Neurosci 26:1571-1578.

Morrow BA, Elsworth JD, Roth RH (2005) Prenatal exposure to cocaine selectively disrupts the development of parvalbumin containing local circuit neurons in the medial prefrontal cortex of the rat. Synapse 56:1-11.

Muir JL (1997) Acetylcholine, aging, and Alzheimer's disease. Pharmacol Biochem Behav 56:687-696.

Nestler EJ (2001) Molecular basis of long-term plasticity underlying addiction. Nat Rev Neurosci 2:119-128.

Pierce JP, Kurucz O, Milner TA (1999) The morphometry of a peptidergic transmitter system before and after seizure. I. Dynorphin B-like immunoreactivity in the hippocampal mossy fiber system. Hippocampus 9:255-276.

Popper CW (1997) Antidepressants in the treatment of attention-deficit/ hyperactivity disorder. J Clin Psychiatry 58 [Suppl 14]:14-29; discussion $30-31$.

Ramos A, Mormede P (1998) Stress and emotionality: a multidimensional and genetic approach. Neurosci Biobehav Rev 22:33-57.

Rapport MD, Moffitt C (2002) Attention deficit/hyperactivity disorder and methylphenidate. A review of height/weight, cardiovascular, and somatic complaint side effects. Clin Psychol Rev 22:1107-1131.

Rice D, Barone Jr S (2000) Critical periods of vulnerability for the develop- 
ing nervous system: evidence from humans and animal models. Environ Health Perspect 108:511-533.

Robinson TE, Kolb B (1999) Alterations in the morphology of dendrites and dendritic spines in the nucleus accumbens and prefrontal cortex following repeated treatment with amphetamine or cocaine. Eur J Neurosci 11:1598-1604.

Romijn HJ, Hofman MA, Gramsbergen A (2000) At what age is developing rat cortex comparable to that of the full term human baby? Early Hum Dev 26:61-67.

Russell V, de Villiers A, Sagvolden T, Lamm M, Taljaard J (1998) Differences between electrically-, Ritalin- and D-amphetamine-stimulated release of $[3 \mathrm{H}]$ dopamine from brain slices suggest impaired vesicular storage of dopamine in an animal model of attention-deficit hyperactivity disorder. Behav Brain Res 94:163-171.

Sagvolden T, Sergeant JA (1998) Attention deficit/hyperactivity disorderfrom brain dysfunctions to behaviour [editorial]. Behav Brain Res 94:1-10.

Scharfman HE, Goodman JH, Sollas AL (2000) Granule-like neurons at the hilar/CA3 border after status epilepticus and their synchrony with area CA3 pyramidal cells: functional implications of seizure-induced neurogenesis. J Neurosci 20:6144-6158.

Schiffer WK, Volkow ND, Fowler JS, Alexoff DL, Logan J, Dewey SL (2006) Therapeutic doses of amphetamine or methylphenidate differentially increase synaptic and extracellular dopamine. Synapse 59:243-251.

Seki T, Arai Y (1993) Highly polysialylated neural cell adhesion molecule (NCAM-H) is expressed by newly generated granule cells in the dentate gyrus of the adult rat. J Neurosci 13:2351-2358.

Sesack SR, Snyder CL, Lewis DA (1995) Axon terminals immunolabeled for dopamine or tyrosine hydroxylase synapse on GABA-immunoreactive dendrites in rat and monkey cortex. J Comp Neurol 363:264-280.

Sesack SR, Hawrylak VA, Matus C, Guido MA, Levey AI (1998) Dopamine axon varicosities in the prelimbic division of the rat prefrontal cortex exhibit sparse immunoreactivity for the dopamine transporter. J Neurosci 18:2697-2708.

Severi S, Guidi S, Ciani E, Bartesaghi R (2005) Sex differences in the stereological parameters of the hippocampal dentate gyrus of the guinea-pig before puberty. Neuroscience 132:375-387.

Silver LB (1999) Attention deficit hyperactivity disorder. A clinical guide to diagnosis and treatment. Washington DC: American Psychiatric.

Solanto MV (1998) Neuropsychopharmacological mechanisms of stimulant drug action in attention-deficit hyperactivity disorder: a review and integration. Behav Brain Res 94:127-152.

Spencer SJ, Buller KM, Day TA (2005) Medial prefrontal cortex control of the paraventricular hypothalamic nucleus response to psychological stress: possible role of the bed nucleus of the stria terminalis. J Comp Neurol 481:363-376.

Swanson LW (1992) Brain maps: structure of the rat brain. Amsterdam: Elsevier.

Swanson JM, Sergeant JA, Taylor E, Sonuga-Barke EJ, Jensen PS, Cantwell DP (1998) Attention-deficit hyperactivity disorder and hyperkinetic disorder. Lancet 351:429-433.
Torres-Reveron A, Dow-Edwards DL (2005) Repeated administration of methylphenidate in young, adolescent, and mature rats affects the response to cocaine later in adulthood. Psychopharmacology (Berl) 181:38-47.

Volkow ND, Wang GJ, Fowler JS, Logan J, Angrist B, Hitzemann R, Lieberman J, Pappas N (1997) Effects of methylphenidate on regional brain glucose metabolism in humans: relationship to dopamine D2 receptors. Am J Psychiatry 154:50-55.

Volkow ND, Wang GJ, Fowler JS, Gatley SJ, Logan J, Ding YS, Hitzemann R, Pappas N (1998) Dopamine transporter occupancies in the human brain induced by therapeutic doses of oral methylphenidate. Am J Psychiatry 155:1325-1331.

Volkow ND, Fowler JS, Gatley SJ, Dewey SL, Wang GJ, Logan J, Ding YS, Franceschi D, Gifford A, Morgan A, Pappas N, King P (1999a) Comparable changes in synaptic dopamine induced by methylphenidate and by cocaine in the baboon brain. Synapse 31:59-66.

Volkow ND, Wang GJ, Fowler JS, Logan J, Gatley SJ, Wong C, Hitzemann R, Pappas NR (1999b) Reinforcing effects of psychostimulants in humans are associated with increases in brain dopamine and occupancy of $\mathrm{D}(2)$ receptors. J Pharmacol Exp Ther 291:409-415.

Volkow ND, Wang GJ, Fowler JS, Logan J, Gerasimov M, Maynard L, Ding YS, Gatley SJ, Gifford A, Franceschi D (2001) Therapeutic doses of oral methylphenidate significantly increase extracellular dopamine in the human brain. J Neurosci 21:RC121(1-5).

Wargin W, Patrick K, Kilts C, Gualtieri CT, Ellington K, Mueller RA, Kraemer G, Breese GR (1983) Pharmacokinetics of methylphenidate in man, rat and monkey. J Pharmacol Exp Ther 226:382-386.

Westwood SC, Hanson GR (1999) Effects of stimulants of abuse on extrapyramidal and limbic neuropeptide Y systems. J Pharmacol Exp Ther 288:1160-1166.

Wigal T, Greenhill L, Chuang S, McGough J, Vitiello B, Skrobala A, Swanson J, Wigal S, Abikoff H, Kollins S, McCracken J, Riddle M, Posner K, Ghuman J, Davies M, Thorp B, Stehli A (2006) Safety and tolerability of methylphenidate in preschool children with ADHD. J Am Acad Child Adolesc Psychiatry 45:1294-1303.

Willuhn I, Sun W, Steiner H (2003) Topography of cocaine-induced gene regulation in the rat striatum: relationship to cortical inputs and role of behavioural context. Eur J Neurosci 17:1053-1066.

Yano M, Steiner H (2005a) Methylphenidate (Ritalin) induces Homer 1a and zif 268 expression in specific corticostriatal circuits. Neuroscience 132:855-865.

Yano M, Steiner H (2005b) Topography of methylphenidate (Ritalin)induced gene regulation in the striatum: differential effects on c-fos, substance P and opioid peptides. Neuropsychopharmacology 30:901-915.

Yano M, Beverley JA, Steiner H (2006) Inhibition of methylphenidateinduced gene expression in the striatum by local blockade of D1 dopamine receptors: interhemispheric effects. Neuroscience 140:699-709.

Zito JM, Safer DJ, dosReis S, Gardner JF, Boles M, Lynch F (2000) Trends in the prescribing of psychotropic medications to preschoolers. JAMA 283: 1025-1030. 